\title{
FLUXOS DE RADIAÇÃO SOLAR GLOBAL EM VINHEDOS DE ALTITUDE DE SÃO JOAQUIM-SC ${ }^{1}$
}

\author{
CLAUDIA GUIMARÃES CAMARGO CAMPOS², HAMILTON JUSTINO VIEIRA \\ ÁLVARO JOSE BACK ${ }^{4}$, APARECIDO LIMA DA SILVA 5
}

RESUMO - O presente trabalho teve como objetivo avaliar e quantificar a partição de energia solar em cultivos de videira (Vitis vinifera L.) em São Joaquim-SC. Consideraram-se três diferentes posicionamentos dos sensores de radiação solar global: voltados para leste, oeste e no topo do dossel. Observou-se que, em plantas de videira conduzidas em espaldeira e posicionadas no sentido norte-sul, o ciclo diurno de radiação solar global apresentou características diferentes entre as faces leste e oeste do dossel, tanto em relação à disponibilidade, quanto à intensidade de radiação. Verificou-se que é em torno das $10 \mathrm{~h}$ que ocorre a maior disponibilidade de radiação solar na face leste $\left(363 \mathrm{~W} \cdot \mathrm{m}^{-2}\right)$ e na face oeste ocorre próximo das $16 \mathrm{~h}\left(290 \mathrm{~W} \cdot \mathrm{m}^{-2}\right)$. A máxima disponibilidade de radiação solar global no topo do dossel é registrada próximo das $13 \mathrm{~h}\left(612 \mathrm{~W} \cdot \mathrm{m}^{-2}\right)$. Cerca de 30\% a 40\% da radiação solar global incidente está disponível nas faces leste e oeste do dossel, com valor superior para a face o leste. Na região de estudo, observou-se maior disponibilidade de radiação solar global nos meses de novembro e dezembro, período que correspondeu ao maior crescimento dos ramos da videira. Termos para indexação: uvas viníferas, irradiação solar, climatologia.

\section{THE GLOBAL SOLAR RADIATION FLOW ON ALTITUDE VINEYARDS IN SÃO JOAQUIM,STATE OF SANTA CATARINA}

\begin{abstract}
This study aimed to evaluate and quantify the partition of energy in wine grape vineyards (Vitis vinifera L.), in São Joaquim/SC. It was considered three distinct positions of the solar radiation sensors: facing east, west and at the top of the canopy. It was observed that in vineyards conducted using the trellis system and positioned north-south, the diurnal cycle of solar radiation presents different characteristics at the east and west sides of the canopy, both in relation to the availability, as well as the intensity of radiation. On average, around 10a.m. that occurs the greater availability of solar radiation incident by the sensor facing East $\left(363 \mathrm{~W} \cdot \mathrm{m}^{-2}\right)$ and by the sensor facing West occurs around $4 \mathrm{p} . \mathrm{m} .\left(290 \mathrm{~W} \cdot \mathrm{m}^{-2}\right)$. The maximum solar radiation incidence on the canopy, average daily cycle, is recorded close to $13 \mathrm{p} . \mathrm{m}$. $\left(612 \mathrm{~W} \cdot \mathrm{m}^{-2}\right)$. Approximately $30 \%$ to $40 \%$ of the incident solar radiation is available to the east and west sides of the canopy, with superior value to face east. In the study area, there was greater availability of solar radiation in the months of November and December, a period that corresponded to the greater growth of the vine branches.
\end{abstract}

Index terms: wine grape, solar radiation, climatology.

\footnotetext{
1(Trabalho 014-13). Recebido em: 03-01-2013. Aceito para publicação em: 16-09-2013.

${ }^{2}$ Meteorologista, Dra., Bolsista PNPD/Capes, UFSC/Epagri/Ciram, Florianópolis-SC, fone (49) 2101 9299. E-mail: cgccampos@ yahoo.com.br

${ }^{3}$ Eng. Agrônomo, Ph.D., Pesquisador da Epagri/Ciram, Florianópolis-SC. E-mail: vieira@epagri.sc.gov.br

${ }^{4}$ Eng. Agrônomo, Ph.D., Pesquisador da Epagri/EEUr, Urussanga-SC. E-mail:ajb@epagri.sc.gov.br

${ }^{5}$ Eng.Agrônomo, Dr., Professor da UFSC/CCA, Florianópolis-SC. E-mail: alsilva@cca.ufsc.br
} 


\section{INTRODUÇÃO}

Entre os vários fatores que intervêm na produção vitícola, o clima e suas características microclimáticas exercem forte influência sobre a videira, sendo determinantes na qualidade da uva e do vinho (ORDUÑA, 2010) e na potencialidade de uma região para a adaptação e produção. Variáveis climáticas, tais como a temperatura do ar, a radiação solar, a umidade relativa do ar e a precipitação exercem influência direta nas diferentes fases de desenvolvimento da videira. A produção de uvas para elaboração de vinhos finos é favorecida pela alta disponibilidade de radiação solar e baixa precipitação durante o período de maturação (SANTOS et al., 2011).

A intensidade luminosa e o total de energia acumulada têm efeitos importantes na fase de floração da videira. Os ramos que recebem maior quantidade de luz têm melhor fecundidade que um ramo sombreado. A temperatura, consequência da exposição solar, também influencia na formação de meristemas florais. A proporção de flores que se desenvolvem normalmente e convertem-se em frutos pode variar de acordo com as características do clima. Situações de sombreamento intenso reduzem notavelmente a frutificação (CHAVARRIA et al., 2009).

A videira é uma planta que requer elevada insolação durante o período vegetativo, sendo um fator importante no processo da fotossíntese, bem como na definição da composição química da uva. Os açúcares são os produtos finais resultantes da atividade fotossintética nos vegetais, sendo este o único processo de importância biológica que possibilita o aproveitamento da energia a partir da luz solar (CHAVARRIA et al., 2009). A concentração de açúcares nas bagas é uma das mais importantes características para o processo de vinificação, sendo o vinho o resultado da transformação fermentativa dos açúcares da uva (glicose e frutose) em álcool (CONDE et al., 2007). Em períodos de maior insolação, por exemplo, as uvas atingem altas concentrações de açúcares nas bagas.

A disponibilidade de radiação solar no ambiente de cultivo diferencia-se conforme a posição do Sol ao longo do dia, de acordo com o ângulo de incidência dos raios solares, determinando, deste modo, parâmetros descritivos entre os fluxos de radiação e as características do dossel (CARDOSO et al., 2010). Os efeitos da intercepção da radiação solar pelo dossel são determinantes na produtividade e na qualidade das uvas. Estudos realizados por Bergqvist et al. (2001) demonstraram o quanto os cachos são influenciados pelas variações diárias de radiação. Cachos da variedade Cabernet Sauvignon expostos à radiação direta durante todo o dia, apresentaram um aumento simultâneo na temperatura das bagas e menores teores de antocianinas e polifenóis totais na casca, quando comparados a cachos que receberam apenas luz difusa no período da tarde. Spayd et al. (2002), examinando a orientação de plantio nortesul da variedade Merlot, observaram que os frutos dispostos no lado leste e que receberam radiação apenas no período da manhã, tiveram maiores teores de antocianinas do que os frutos localizados na parte oeste, expostos à radiação no período da tarde. Segundo os autores, além dos efeitos da radiação, também são considerados os efeitos da temperatura do ar, sendo que, para regiões quentes, a exposição prolongada dos frutos à luz direta do sol deve ser evitada.

O presente estudo teve como objetivo avaliar e quantificar a energia solar disponível em cultivos da videira (Vitis vinifera L.) em regiões de altitude de São Joaquim-SC. Foram considerados três diferentes posicionamentos dos sensores de radiação solar global: a leste, oeste e no topo do dossel.

\section{MATERIAL E MÉTODOS}

Os valores horários de radiação solar global incidentes $\left(\mathrm{W} . \mathrm{m}^{-2}\right)$ foram obtidos de uma estação meteorológica automática, instalada junto a vinhedos da empresa Vinícola Villa Francioni, localizada no município de São Joaquim-SC ( $28^{\circ} 15^{\prime} 14^{\prime \prime}$ S, $49^{\circ}$ 57' 02”'W e $1294 \mathrm{~m}$ de altitude). O clima da região, de acordo com a classificação de Köppen, é do tipo $C f b$ (temperado), com as quatro estações do ano bem definidas e com baixas temperaturas do ar no inverno. Os meses mais quentes são janeiro e fevereiro, com temperatura média em torno de $17^{\circ} \mathrm{C}$, enquanto o mês mais frio é julho, com média de $9,4^{\circ} \mathrm{C}$.

A estação meteorológica possui um sistema de aquisição de dados CR1000 da Campbell Scientific. Os sensores de radiação solar global (Kipp \& Zonen, model CUV3) foram instalados em três orientações diferenciadas: sensor voltado para leste (E), para oeste do dossel (W), ambos a 1,60 $\mathrm{m}$ acima do solo, e no topo do dossel vegetativo, sobre as plantas de videira a 3,00 m do solo. Para a avaliação da radiação solar global incidente $(Q g)$, foi considerado o período de outubro de 2008 a dezembro de 2011.

Os dados de radiação extraterrestre $(Q o)$ foram calculados com base na latitude e na época do ano, através das equações descritas abaixo:

$Q o=\frac{24(60)}{\pi} G_{s c} d r\left[\varpi_{s} \operatorname{sen}(\varphi) \operatorname{sen}(\delta)+\cos (\varphi) \cos (\delta) \operatorname{sen}\left(\varpi_{s}\right)\right]$ 
Em que:

$Q o=$ Radiação extraterrestre $\left(\mathrm{MJm}^{-2} \mathrm{dia}^{-1}\right)$;

$G s c=$ constante solar $=0,0820 \mathrm{MJm}^{-2} \mathrm{dia}^{-1}$;

$d r=$ Distância relativa inversa Terra-Sol;

$\omega s=$ Ângulo horário pôr do Sol (radiano);

$\varphi=$ Latitude local (radiano);

$\delta=$ Declinação solar (radiano);

A distância relativa Terra-Sol é dada por:

$d r=1+0,033 \cos \left(\frac{2 \pi}{365} D J\right)$, em que $D J=$ Dia Juliano

A declinação solar ( $\delta$ ) é dada por:

$\delta=0,409 \operatorname{sen}\left(\frac{2 \pi}{365} D J-1,39\right)$

O ângulo horário pôr do Sol $\left(\omega_{s}\right)$ é dado:

$$
\varpi_{s}=\operatorname{arcos}[(-\tan (\varphi) \tan (\delta)]
$$

O índice de transmissividade $\left(K_{T}\right)$ foi definido como a razão entre a radiação solar global observada $(Q g)$ e a radiação solar que chega ao topo da atmosfera $(Q o)$. Este índice foi calculado usando-se a expressão: $K_{T}=Q g$ / $Q o$

A radiação solar difusa diária, para a face leste do dossel, foi medida no período matutino com o sensor voltado para a face oeste. O contrário foi empregado para a determinação da radiação difusa da face oeste do dossel. Considerou-se o ponto de máxima radiação solar global incidente, no topo do dossel, o ponto de intersecção entre os fluxos de radiação de leste e oeste. A radiação solar difusa total foi determinada somando os fluxos de radiação difusa, a leste e oeste do dossel.

Os dados de crescimento dos ramos foram coletados em vinhedos implantados em 2002, com as variedades Cabernet Sauvignon e Merlot, enxertadas sobre Paulsen 1103, no sistema de condução espaldeira, com espaçamentos de 3,00 m entre filas e $0,75 \mathrm{~m}$ entre plantas (BORGHEZAN et al., 2012). O dossel inicia-se a 1,50 metro de altura acima do solo, até 3,00 $\mathrm{m}$ de altura, com orientação das filas norte-sul.

Através de análises estatísticas descritivas e de métodos de correlações lineares, os dados foram analisados em três diferentes escalas temporais: horária, diária e mensal, possibilitando, desta forma, observar as variações diárias e mensais da radiação solar global e extraterrestre, em cada face do dossel e de seus efeitos no crescimento dos ramos da videira.

\section{RESULTADOS E DISCUSSÃO}

Observou-se que em cada uma das faces do dossel (leste, oeste e topo) os fluxos diários de radiação solar apresentaram características distintas, variando em função do ângulo de incidência do fluxo de radiação solar. Os fluxos diários de radiação solar distinguiram-se de acordo com o posicionamento do sensor, sendo as principais diferenças observadas entre os sensores voltados para os sentidos leste e oeste. No sensor voltado para leste, a maior incidência foi observada no período da manhã, entre $9 \mathrm{~h}$ e $10 \mathrm{~h}$, e para o sensor de oeste, entre $15 \mathrm{~h}$ e $16 \mathrm{~h}$. O sensor instalado no topo do dossel representa o fluxo diurno total de radiação solar global, com valores máximos entre $12 \mathrm{~h}$ e $13 \mathrm{~h}$, conforme pode ser observado na Figura 1. Segundo Schultz et al. (2009), a taxa fotossintética inicia com a captação da energia solar nas primeiras horas da manhã, alcançando um nível máximo que se mantém até o final do dia, quando reduz drasticamente, acompanhando a variação do movimento aparente do Sol, ou seja, sendo maior na face leste pela manhã e oeste durante a tarde.

Através da área sombreada (cinza), na Figura 1, é possível representar a radiação difusa no dossel, cujo valor máximo foi de aproximadamente $142 \mathrm{~W} . \mathrm{m}$ ${ }^{2}$, entre as $12 \mathrm{~h}$ e as $13 \mathrm{~h}$. Observou-se também que, no início da manhã (entre as 6 e as 9 h) e no final de tarde (entre 17 e 19 h), as radiações incidentes nos sensores voltados para leste e oeste, respectivamente, apresentam valores muito próximos à radiação global incidente no topo do dossel. No horário em que a radiação solar no topo do dossel foi máxima, entre 12 e 13 h, nos sensores leste e oeste, a radiação solar incidente é equivalente à radiação difusa, pois devido à posição dos mesmos não recebem radiação solar direta. Para Bergqvist et al. (2001), os cachos das variedades Carbernet Sauvignon e Grenache, quando expostos à radiação direta durante todo o dia, tiveram um aumento simultâneo na temperatura das bagas e apresentaram menores teores de antocianinas e polifenóis totais na casca, quando comparados a cachos que recebiam apenas luz difusa no período da tarde. No trabalho em questão, verificou-se que a radiação solar global direta e difusa foi similar nas faces leste e oeste do dossel, mostrando não ocorrer possíveis influências nas plantas de videira, quando considerados os períodos matutino e vespertino.

A Figura 2 representa as variações horárias de radiação solar nos meses avaliados. Comparando-se o fluxo de radiação global incidente no sensor leste, na parte da manhã, com o fluxo de radiação incidente no sensor oeste, na parte da tarde, verifica-se, que entre os meses de novembro e abril, os valores de 
fluxos horários de radiação são maiores no sensor leste do que no sensor oeste, em especial no verão, o que significa maior quantidade de radiação solar incidente disponível no período da manhã. Esta diferença observada está associada a fatores atmosféricos, tais como: presença de nebulosidade e elevada umidade relativa do ar. No período da tarde, em meses com temperatura do ar mais elevada, há um aumento de nebulosidade por processos de convecção atmosférica, aumentando a interceptação da radiação solar global.

Na Figura 3, observa-se a variação anual da radiação solar global incidente no sensor do topo do dossel, da radiação extraterrestre incidente no topo da atmosfera e do índice de transmissividade $\left(\mathrm{K}_{\mathrm{T}}\right)$, representados em dias julianos, em que o dia 152 representa o início do mês de junho. É possível visualizar a atenuação da radiação solar global. Nos meses de inverno, de junho a agosto, ocorrem mais frequentemente incursões de massas de ar seco, provocando uma menor atenuação da radiação solar incidente. Em escala diária, o índice de transmissividade variou em grande amplitude, no intervalo de 0,1 a 0,8 (Figura 3). A média observada foi de 0,5 , indicando que a radiação solar global incidente na superfície terrestre local, equivale a $50 \%$ da radiação incidente no topo da atmosfera. Estes valores estão de acordo com os determinados por Vieira et al. (2011), nas condições do planalto catarinense.

Ao analisar as médias mensais de radiação solar global (Figura 4), nos sensores voltados para leste e oeste, observou-se uma diferença entre as médias mensais de radiação solar incidente no período de novembro a março. Os valores superiores de radiação foram observados no período da manhã, no sensor voltado para leste. No topo do dossel, entre o início da primavera (setembro) e o início do outono (março), há maior incidência de radiação solar em relação aos demais meses (Figura 4), período equivalente ao desenvolvimento vegetativo da videira.

Na Tabela 1, são apresentados, os valores mensais e anuais, da radiação solar global e difusa $\left(\mathrm{W} . \mathrm{m}^{-2}\right)$ e seus respectivos valores, em percentagem, relacionando-os com a radiação solar incidente no topo do dossel. Da radiação média incidente no topo do dossel 39\% equivalem à radiação que chega ao sensor voltado para o leste e $36 \%$ no sensor oeste. Ou seja, cerca de 30\% a 40\% da radiação solar global incidente no topo do dossel estão disponíveis para as folhas e frutos nas faces leste e oeste. Observou-se que, mesmo nos períodos com maior disponibilidade de radiação solar global incidente, a radiação difusa demonstrou pouca variação nos valores. A disponibilidade de radiação difusa varia de 10 a $18 \mathrm{~W} \cdot \mathrm{m}^{-2}$, na face leste do dossel, e entre 8 e $20 \mathrm{~W} \cdot \mathrm{m}^{-2}$ na face oeste. A radiação difusa total é equivalente acerca de $15 \%$ da radiação solar global incidente no topo do dossel. Observou-se que, nos meses de outubro a dezembro e no mês de abril, há uma maior disponibilidade de radiação solar difusa com maior contribuição para a face oeste (Tabela 1).

A Figura 5 apresenta os valores de crescimento dos ramos de duas variedades de videira (Cabernet Sauvignon e Merlot). Observou-se um ciclo de crescimento vegetativo até 144 dias, iniciando em 15 de setembro e terminando em 06 de fevereiro. A maior taxa de crescimento do ramo ocorre, em média, com 73 dias de desenvolvimento, ou seja, entre o final de novembro e o início de dezembro, período no qual ocorre o máximo de radiação solar global. A partir do final de novembro e início de dezembro (73 a 81 dias do ciclo), período de máxima disponibilidade de radiação solar, a videira atinge cerca de $70 \%$ do comprimento máximo do ramo (em média 3,2 $\mathrm{m}$ ). Após este período, todas as variedades reduzem drasticamente o crescimento, com uma taxa inferior a 0,26 (Figura 5). Ressalta-se que os valores de crescimento dos ramos apresentaram alta correlação entre das variedades estudadas $(0,97)$, considerando desde o início do crescimento (depois da brotação) até o instante em que os ramos paralisaram o crescimento (início da maturação - 144 dias).

Verificou-se que, entre o final de novembro e o início de dezembro, período no qual ocorre o máximo de radiação solar global, Borghezan et al. (2012) observaram maior taxa de crescimento dos ramos para videiras cultivadas em São Joaquim. Estes autores também descreveram que a videira paralisou o crescimento vegetativo no início de fevereiro, período este em que também se observou redução nos valores de radiação global (Figura 4). 


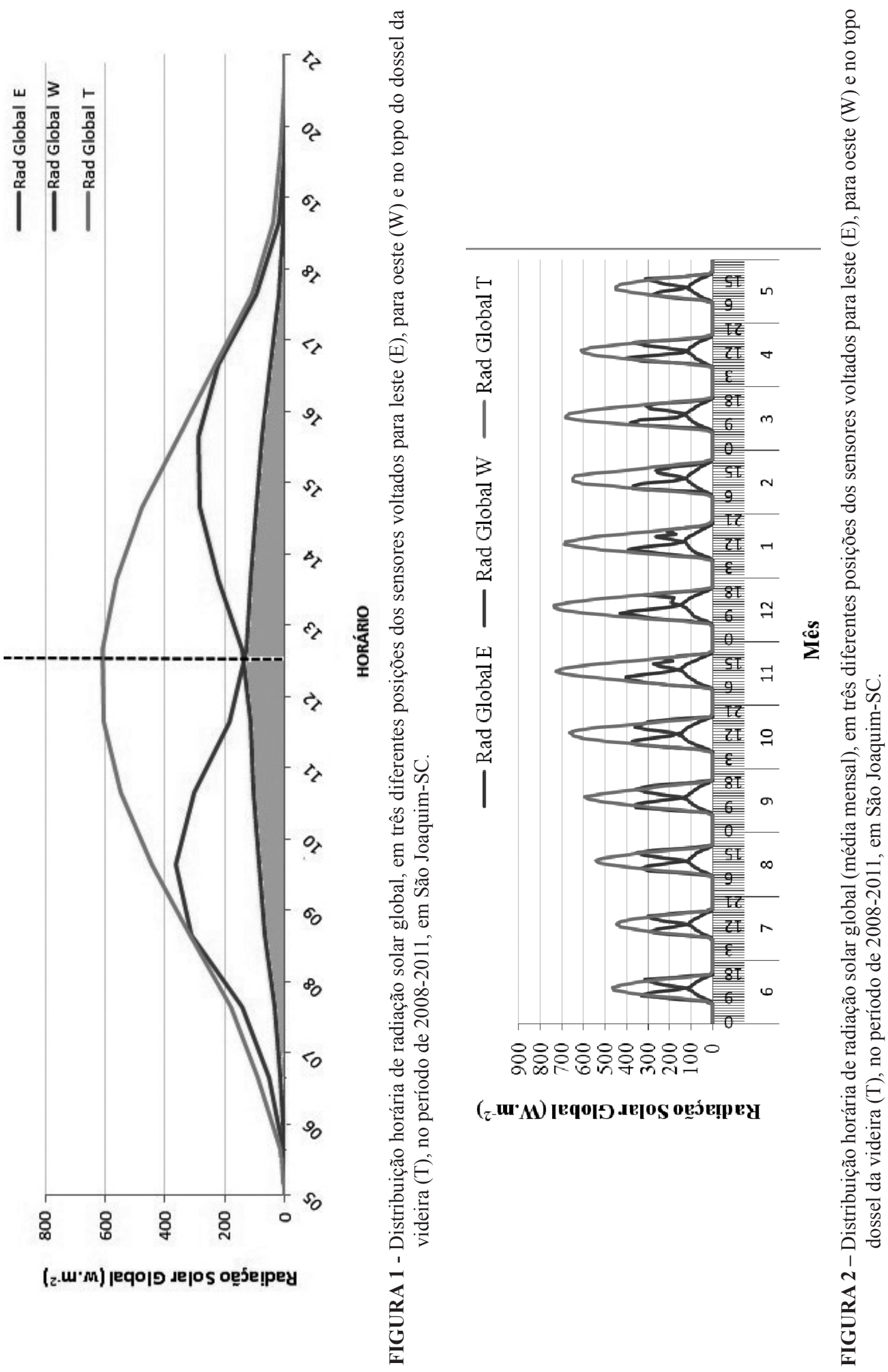




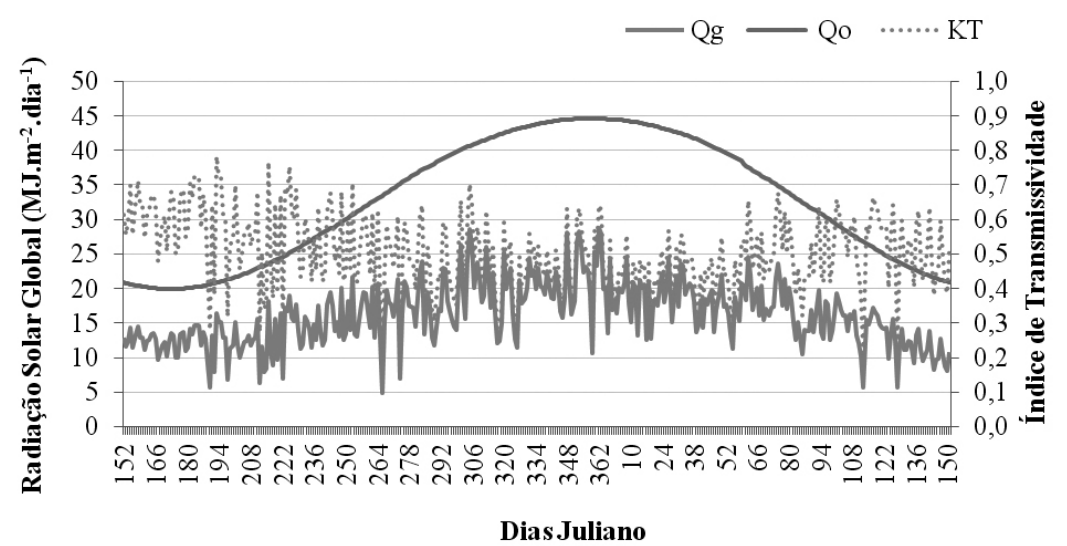

FIGURA 3 - Variação anual da radiação solar global diária $\left(\mathrm{Q}_{\mathrm{g}}\right)$ medida no topo do dossel de vinhedos de altitude (São Joaquim-SC), da radiação solar extraterrestre calculada (Qo) e da transmissividade atmosférica $\left(\mathrm{K}_{\mathrm{T}}\right)$.

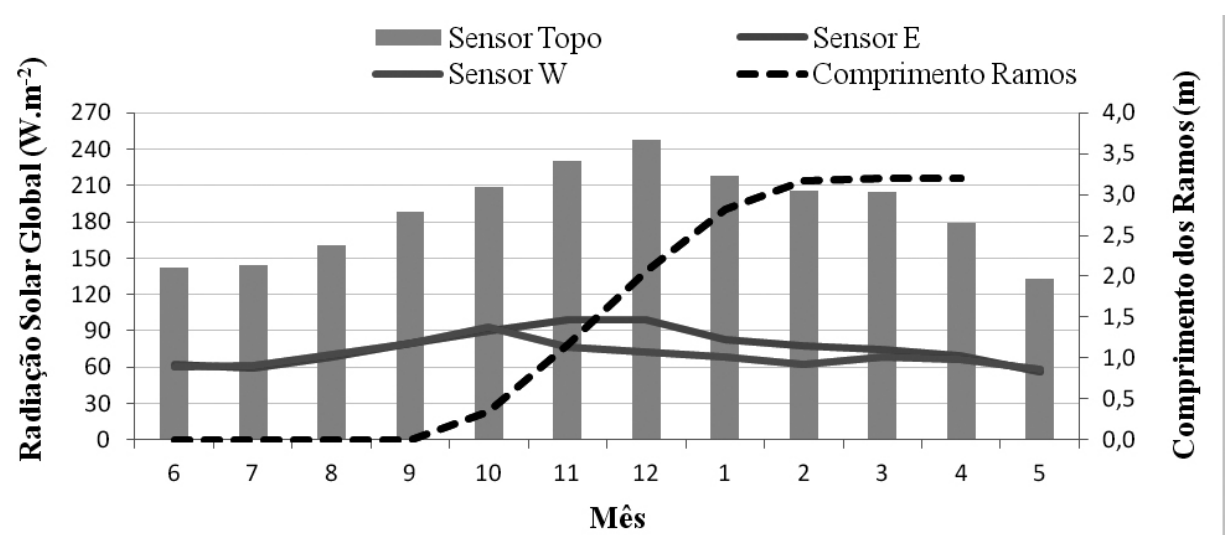

FIGURA 4 - Variação mensal de radiação solar global, em três diferentes orientações dos sensores, leste (E), oeste (W) e topo do dossel da videira, no período de 2008-2011, em São Joaquim-SC. A linha tracejada representa o comprimento médio dos ramos (metros) da videira.

- Crescimento Médio $\square$ Taxa crescimento

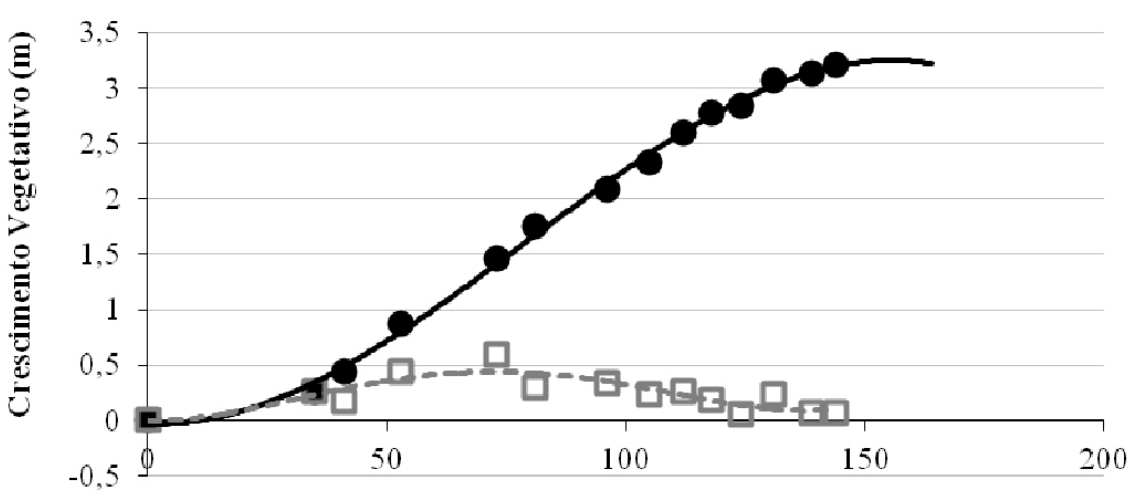

\section{Dias Juliano}

FIGURA 5 - Curvas do crescimento médio e taxa de crescimento dos ramos, em ciclo de 144 dias, São Joaquim-SC (Borghezan et al., 2012). 
TABELA 1 - Valores médios mensais de radiação solar global e da radiação difusa, no período de 2008 a 2011, em São Joaquim-SC.

\begin{tabular}{|c|c|c|c|c|c|c|c|c|c|c|}
\hline \multirow{2}{*}{ SENSOR } & \multicolumn{3}{|c|}{$\begin{array}{l}\text { Radiação global } \\
\text { (W.m-2) }\end{array}$} & \multicolumn{3}{|c|}{$\begin{array}{c}\text { Radiação difusa } \\
\left(\mathbf{W} \cdot \mathbf{m}^{-2}\right)\end{array}$} & \multicolumn{3}{|c|}{$\begin{array}{l}\text { Radiação global em } \\
\text { relação à radiação global } \\
\text { do topo do dossel (\%) }\end{array}$} & \multirow[t]{2}{*}{$\begin{array}{l}\text { Radiação difusa } \\
\text { total em relação } \\
\text { à rad. global do } \\
\text { topo do dossel } \\
(\%)\end{array}$} \\
\hline & Leste & Oeste & Topo & Leste & Oeste & Total & Leste & Oeste & Total & \\
\hline 6 & 62 & 61 & 143 & 14 & 12 & 26 & 43 & 43 & 86 & 18 \\
\hline 7 & 59 & 62 & 145 & 11 & 8 & 19 & 41 & 43 & 84 & 13 \\
\hline 8 & 69 & 71 & 161 & 12 & 9 & 21 & 43 & 44 & 87 & 13 \\
\hline 9 & 80 & 80 & 188 & 14 & 11 & 25 & 42 & 43 & 85 & 13 \\
\hline 10 & 90 & 93 & 209 & 18 & 17 & 35 & 43 & 45 & 88 & 17 \\
\hline 11 & 99 & 76 & 230 & 15 & 20 & 35 & 43 & 33 & 76 & 16 \\
\hline 12 & 99 & 72 & 248 & 12 & 19 & 31 & 40 & 29 & 69 & 12 \\
\hline 1 & 83 & 69 & 218 & 10 & 12 & 22 & 38 & 32 & 70 & 10 \\
\hline 2 & 77 & 62 & 205 & 12 & 13 & 25 & 38 & 30 & 68 & 12 \\
\hline 3 & 74 & 68 & 205 & 14 & 15 & 29 & 36 & 33 & 69 & 14 \\
\hline 4 & 69 & 67 & 179 & 16 & 16 & 32 & 39 & 37 & 76 & 18 \\
\hline 5 & 56 & 58 & 133 & 16 & 13 & 29 & 42 & 44 & 86 & 22 \\
\hline ANUAL & 77 & 70 & 195 & 14 & 14 & 28 & 39 & 36 & 75 & 15 \\
\hline
\end{tabular}

\section{CONCLUSÕES}

1-A radiação solar global incidente nas faces leste e oeste do dossel vegetativo da videira corresponde acerca de $30 \%$ a $40 \%$ da radiação total medida acima do dossel.

2-No período da manhã, na face leste do dossel, ocorre maior radiação solar incidente em relação à face oeste, no período da tarde.

3- O plantio da videira no sentido norte-sul, conduzida em espaldeira recebe radiação solar durante todo o dia.

4-Nas regiões de altitude, os períodos de maior disponibilidade de radiação solar no dossel correspondem aos períodos de maior crescimento dos ramos da videira, que ocorre no final da primavera e início do verão (novembro/dezembro).

\section{AGRADECIMENTOS}

Os autores agradecem à CAPES/PNPD, pelo auxílio financeiro, à UFSC/RGV e Epagri/Ciram, pelo apoio e a oportunidade de execução deste trabalho.

\section{REFERÊNCIAS}

BERGQVIST, J.; DOKOOZLIAN, N.; EBISUDA, N. Sunlight Exposure and Temperature Effects on Berry Growth and Composition of Cabernet Sauvignon and Grenache in the Central San Joaquin Valley of California. American Journal of Enology and Viticulture, Davis, v. 52, n. 1, p. 1-7, 2001.

BORGHEZAN, M.; GAVIOLI, O.; VIEIRA, H.; SILVA, A. Shoot growth of Merlot and Cabernet Sauvignon grapevine varieties. Pesquisa Agropecuária Brasileira, Brasília, v. 47, n. 2, 2012. 
CARDOSO, L. S.; BERGAMASCHI, H.; COMIRAN, F.; CHAVARRIA. G.; MARODIN, G. A. B.; DAlmago, G. A.; SANTOS, H. P. dos; MANDELLI, F. Padrões de interceptação de radiação solar em vinhedos com e sem cobertura plástica. Revista Brasileira de Fruticultura, Jaboticabal, v. 32, n. 1, p. 161-171, 2010.

CHAVARRIA, G.; SANTOS, H. P. dos; MANDELLI, F.; MARODIN, G. A. B.; BERGAMASCHI, H.; CARDOSO, L. S. Caracterização fenológica e requerimento térmico da cultivar Moscato Giallo sob cobertura plástica. Revista Brasileira de Fruticultura, Jaboticabal, v. 31, n. 1, p. 119-126, 2009.

CONDE, C.; FONTES, N.; DIAS, A.C.P.; TAVARES, R.M.;SOUZA, M.J.; AGASSE, A.; DELROT, S.; GERÓS, H. Biochemical changes throughout grape berry development and fruit and wine quality. Food, Tokyo, v. 1, n. 1, p. 1-22, 2007.

ORDUÑA, R. M. de. Climate change associated effects on grape and wine quality and production. Food Research International, Davis, v.43, p.18441855, 2010.

SANTOS, A. O.; HERNANDES, J. L.; PEDRO JR., MÁRIO J.; ROLIM, G.S. Parâmetros fitotécnicos e condições microclimáticas para videira vinífera conduzida sob dupla poda sequencial. Revista Brasileira de Engenharia Agrícola e Ambiental, Campina Grande, v.15, n.12, p. 1251-1256, 2011.
Disponível em: < http://dx.doi.org/10.1590/S141543662011001200006>. Acesso em: 10 maio 2012.

SCHULTZ, H.R.; PIERI, P.; PONI, S.; LEBON, E. The eco-physiology of grapevine canopy systems - learning from models. In: INTERNATIONAL SYMPOSIUM: RECENT ADVANCES IN GRAPEVINE CANOPY MANAGEMENT, 2009, Davis. Proceedings... 9p.

SPAYD, S.E.; TARARA, J.M.; MEE, D.L.; FERGUSON, J.C. Separation of sunlight and temperature effects on the composition of Vitisvinifera cv. Merlot berries. American Journal of Enology and Viticulture, Davis, v.53, p.171-182, 2002.

VIEIRA, H.J.; BACK, A.J.; SILVA, A.L.; PEREIRA, E.S. Comparação da disponibilidade de radiação solar global e fotoperíodo entre as regiões vinícolas de Campo Belo do Sul-SC, Brasil e Pech Rouge, França. Revista Brasileira de Fruticultura, Jaboticabal, v.33, n. 4, p. 1055-1065, 2011. 